\title{
PECULIARITIES OF FORMING \\ A TOLERANT ATTITUDE OF SCHOOL AND FAMILY \\ TO PRIMARY SCHOOL-AGED CHILDREN
}

\section{Hanna Lulka ${ }^{1}$ \\ Marina Grinova ${ }^{2}$}

DOI: https://doi.org/10.30525/978-9934-588-53-2-19

\begin{abstract}
The study examines the peculiarities of forming a tolerant attitude of the school and the family towards children of primary school age. The concepts of "tolerance" are compared, the similarity in content and the existence of significant differences between them are described. The understanding of tolerance as a basis for the implementation of effective dialogue is revealed, as a certain quality of personality, possession of which is necessary for successful realization of social activity. Along with the concept of interaction comes to the fore the role of the person who carries out this interaction. The synthesized definition of the concept of tolerance as an integrative dynamic of a subject's quality includes an active nature and a valuable basis for relation to other subjects of interaction.

Tolerance is characterized as a professionally important quality of elementary school teacher's personality. Pedagogical tolerance acts as an integrative form that bears the traits of all types and levels of tolerance, determined by the goals, objectives and characteristics of the teacher's pedagogical activity and all the variety of pedagogical situations. Types of interactions that are tolerant are identified: dialogue, collaboration and tutelage. It is emphasized that the main aspects of the problem of tolerance are most clearly manifested in communication, or communicative tolerance. The structure of the tolerant attitude of the teacher towards the students is presented in the form of interaction of three leading components: conceptual-value, activity-behavioral and personalitymotivational. The system of tolerant relations between the teacher and the
\end{abstract}

\footnotetext{
${ }^{1}$ Postgraduate Student of the Department of General Pedagogy and Andragogy, Poltava National Pedagogical University named after V.G. Korolenko, Ukraine

${ }^{2}$ Doctor of Pedagogical Sciences, Professor,

Corresponding Member at the NAES of Ukraine,

Poltava National Pedagogical University named after V.G. Korolenko, Ukraine
}

(C) Hanna Lulka, Marina Grinova 
children is presented as three inseparable parts: understanding, recognition and acceptance of the child.

It is actualized that pedagogical tolerance is an active position that is formed on the basis of recognition of universal rights and fundamental freedoms of each student. The teacher advocates the humanization of the social environment, all means of education, the formation of one's own personality, capable of bringing all these ideas to life, into the real practice of teaching and educating the younger generation on the ideas of peace and understanding. It is important to perceive the child not with criticism, but with optimism, belief in his or her natural abilities and successes.

The level of modern culture challenges parents to learn how to resolve conflicts with children based on the principles of tolerance. A strong family with traditions and tolerant relationships between children and parents counteracts the negative impact of the environment on its members. It has been found that tolerance in the relations between children and parents in the family acts as a certain setting for the perception, understanding and actions of adults and children, based on mutual respect for the interests, values and positions of all family members. It also implies the ability of parents to anticipate the effects of family relationships on the child, his or her development and behavior as a whole based on mutual respect and support. Principles of purposeful process of education of tolerance in relations of children and their parents are analyzed.

\section{Introduction}

A representative of modern society must have a high level of general culture, moral standard, be able to find common ground with other people, which is extremely important for the process of integration and assimilation of cultures. That is why forming a tolerant attitude is one of pedagogical priorities.

The school is one of the most important mechanisms of state influence on solving social problems and ensuring optimal interaction between the participants of the educational process. Successful activity of elementary school teachers in a personality-oriented model of education is possible in case of their tolerant outlook and tolerant behavior.

Because it is the family where children receive an important experience of interacting with people, establishing communication developing ability 
to listen to and respect opinions of other persons, as well as to care patiently about their people, parents are the first and foremost educators of children, and it is impossible to form tolerance in a child unless they are teachers' adherents in the way of forming a tolerant attitude.

The purpose of the study is to analyze the peculiarities of forming a tolerant attitude of the school and the family towards children of primary school age. According to the purpose of the research its task involves analyses of the essence of tolerance, expression of pedagogical tolerance and tolerant relations in the family.

\section{The essence of tolerance}

The notion of "tolerant attitude" is regarded as synonym to the term "tolerance" and, as the analyses of its evolution show, to see that the term roots into. Analysis of the evolution of the term allows us to its roots interpretations in the writings of Renaissance scientists. The term itself emerged during religious wars between the Catholics and the Protestants, that had a significant impact on the philosophical thought in Europe.

After that the most active studies of the phenomenon of tolerance are dated by the second half of the $20^{\text {th }}$ - the beginning of the $21^{\text {st }}$ centuries. The interest to it was mostly initiated with the problem of interpersonal interactions in the multicultural regions of Europe. In understanding the essence of tolerance there appeared differences related to identification it from the related notion of «patience», the origin of which is ambiguous in translating the term into Ukrainian. Thus, the one-root Latin word for "tolerantia" is translated as patience, and «tolerance» as a noun is derived from the verb "tolerare", which means to bear, to hold, to endure. In English there are several single root words: tolerance, tolerate, toleration: religious tolerance (the assumption of religious freedom) [13, p. 7].

On the one hand, we see the similarity of the notions of "tolerance" and "patience", and, on the other, we see the existence of significant differences between them. In the Germanic languages, the meaning of tolerance is limited to the religious notion, while in the Slavic languages it is rather «the ability to put up with something unpleasant». Therefore, the meaning of the translated term is sometimes completely identified with patience, while in other cases it has a religious connotation, approaching to the notion of the tolerance to believes. 
The term "tolerance» has a polyscientific nature. Thus, in the Great Interpretive Dictionary of the Ukrainian language, tolerance is understood as the ability to withstand physical or moral suffering; the desire to find an agreement, to maintain relations with people who are different from the majority; the ability to respect and understand their differences [2, p. 518].

According to Art. 1 of Tolerance Principles Declaration, adopted by the UNESCO General Conference (1995), tolerance means respect, acceptance and a correct understanding of the diversity of cultures of our world, ways of self-expression and manifestation of human personality. This is, first and foremost, an active attitude formed on the basis of recognition of universal human rights and freedoms. Under no circumstances tolerance can be a justification of the encroachment on core values [7].

Analyzing the definition of tolerance in terms of philosophy, we find that in addition to identifying it with the notion of "patience", it has a qualitative difference: tolerance is a sign of self-confidence, one of the conditions for sustainability of a society and peaceful coexistence of the peoples [10, p. 27].

It is particularly emphasized that the philosophy of tolerance implies universal equality. Understanding tolerance as a moral principle and vital value is significant.

In psychology, tolerance is understood as absence or weak response to an unfavorable factor as a result of a decrease in sensitivity to its influence and absolute insensitivity or a significant weakening of the response to social stimulus as a result of no importance of it for an individual [14, p. 12].

In this definition the most significant is the essence of social factor without being limited with anything, therefore, expression of tolerance is not limited only to religious or political context. This allows one to view tolerance not as a reaction to stimuli, but as a personal quality.

In sociology, tolerance is defined as value, social norm and fundamental democratic principle. Here it is important to distinguish two main peculiarities of the notion. Firstly, it is stated that tolerance is of particular importance in the modern world because it is aimed at constructive interaction of social groups with different values, religious and political orientations. And, secondly, the process of asserting tolerance as one of the democratic values in far from being smooth due to "extreme polarization of interests and values of individuals and social groups" [6, p. 23]. 
In pedagogical studies, tolerance is regarded as an educator's professional ability (based on high values and humanistic orientations) to understand, agree to and accept other people as they are: those having different values, logics of thinking, ways of behavior, subjective experience, ability to analyze critically and evaluate subjective experience and behavior through cooperation, compromise, empathy, kindness, etc. (I. I. Sorokin) [17, p. 2].

The notion of tolerance as poly-scientific category, analyzed above, should be complemented with the analysis of current scientific papers. It is important to mention that when comparing two notions of tolerance patience, scientists distinguish the position of the activity - passivity of the subject as a basis for distinguishing them. In particular, L. M. Haidamashchuk believes that tolerance and patience carry different functions and are provided with different mechanisms. Patience, as a property of personality, manifests itself in the increase of sensitivity to the object, while under tolerance, the scientist understands the property of the personality, which is manifested in the same conditions but is characterized by a decrease in sensitivity to the object. The author emphasizes that tolerance, as opposed to patience, is "an active life position of a self-sufficient individual and not a passive patience or obedience" [5, p. 53].

A similar view is expressed by Ye. K. Vyshnevetska, who suggests the following grounds for differentiation of the terms: "...patience tends to the notion of "humility", which reflects the passive position of the subject. Tolerance is an active stance in the attitude towards others.... In turn, an active stance towards the "other" is positive, constructive; it involves mutual benefit and interest of different contact groups" [4, p. 38].

The author emphasizes the leading role of tolerance as a major factor in professional communication between people.

In her research, L. M. Haidamashchuk underlines that the term "tolerance" has changed its meaning over the last 30 years. In comparison with classic definition of tolerance, which includes only reluctant patience and indifference to others, their beliefs and actions, in the neoclassical sense of each person's beliefs, values, behavior, and the criteria, by which she establishes truth, are equally fair and worth recognition [5, p. 53].

Tolerance, previously related only to religious tolerance, is now much broader notion. For a tolerant minded person, it is important to understand and feel how "others" act, what their actions and decisions are based on 
concerning not only faith or cultural peculiarities, but any other scope of life. This change in understanding tolerance emphasizes the current distinction between "tolerance" and "patience".

Such an understanding of tolerance opens the way to dialogue and gives a possibility to build effective interpersonal interaction respecting and recognizing the other's right to a different outlook, while understanding tolerance as patience is an identification of it with moral indifference, that is the tolerance as indifference that close the possibility to effective interaction.

The opposite of tolerance as indifference is moral relativism, when one assimilates and accepts absolutely everything he or she comes in contact with. The difference between tolerance and moral relativism is emphasized by the fact that it does not require an unconditional assignment to any situation. Thus, tolerance is more acceptable for effective quality of life than humble patience that does not allow moral assessment of the facts of reality, or total intolerance, which does not fit into the worldview of "one's own", and a priori is evil.

We should agree with the opinion of scholars who point to the active nature of tolerance and define it as «not only restraint from the use of force against the other one, recognition and respect of views and actions of others, but also respect and appropriation of the others based on selfconfidence...» [13, p. 28]. According to L. Yu. Achasova, "tolerance is not a humble passive obedience, but an active moral stance and psychological willingness for tolerance in the name of understanding..." [1, p. 25]. A. L. Stoliarenko states that tolerance manifests itself in an active moral position, in the setting up for dialogue and mutual understanding with representatives of other environment, including cultural, national, ethnic, religious, social and so on [19, p. 48].

Understanding tolerance as a basis for the implementation of effective dialogue allows to define it as a certain quality of a personality who is based on the values, possession of which is necessary for successful implementation of social activities. This personal quality manifests itself in the activity of the subject and is significant in all aspects of human behavior and existence.

Strengthening of globalization processes in the modern world, increasing the plane of interaction between different human communities, accelerating 
the dynamics of all social processes determines the social demand for tolerance. Tolerance as one of the adaptogenic qualities of an individual, acts in a double way: on the one hand, it serves as a universal tool for conflictfree activity, on the other, it is the object of formation and development. The above-mentioned definition of tolerance reveals a humanistic orientation in enabling the realization of subject-subject relations and indicates the pedagogical problem of its formation.

Due to the variety of accentuated aspects, tolerance is an integrative personal quality. In this aspect, the definition of tolerance as a conscious and value-based personal choice is significant, according to which a person, having his or her own opinion, position and outlook respects and recognizes the right of others to perceive, think and act differently, sees the value of diversity and is ready to construct interaction based on understanding and taking into account different points of view. In this definition, along with the notion of interaction, there comes to the fore the role of the person who carries out this interaction.

The same opinion is expressed by O. M. Kramareva, when she speaks about the expediency of considering tolerance as a personal quality, which acts as a certain set up, emotional and volitional willingness to overcome confrontation in relations with others. She states: «Tolerance is not just a quality alone, but a final factor in the interrelated traits of a personality" $[9$, p. 27].

M. O. Vyhrystiuk notes: "Tolerance is an integrative personal quality based on the value attitude towards people as representatives of other social groups and is expressed in active stance of a person, and implies broadening personal values through positive interaction with other cultures» [3, p. 70].

Important point in this definition is that expression of tolerance is not limited to one aspect of human interaction, but can occur in any situation. Echoing this view is the statement that tolerance reveals a person's ability «to interact with the external environment in problematic and crisis situations in order to restore successful adaptation, prevent confrontation and develop positive relationships with oneself and the world» [16, p. 4]. It also emphasizes the universality of the situation of tolerance, not limited to the allocation of only one type of problematic interaction.

Based on the analysis carried out, the synthesized definition of tolerance includes an active nature and a value oriented basis in attitude to other 
participants of interaction. Therefore, tolerance is an integrative dynamic personality trait of an individual, that expresses itself as a moral principle in the interaction with other people and is based on the value attitude towards people, according to which a person who has his or her own stance, respects and recognizes the right of other people to perceive, think and act differently, sees the value of diversity and is ready to construct interaction taking into account different points of view.

\section{Expression of educational tolerance}

Educational activity is full of all kinds of tense situations associated with increased emotional response to external and internal factors. The external conditions of educational work include: the nature of the tasks to be solved and the responsibility for the functions performed, workload, high intellectual and emotional load, a large number of students in the classroom, the presence of pedagogically neglected students, etc. Among the subjective, internal factors one can point pout the individual properties of the nervous system, the level of sensitivity to professional difficulties, experience, knowledge, skills. Strenuous situations Primary school teacher can have some tense moments within the following situations:

- teacher-student interactions related to discipline violations and ignoring educational requirements;

- interaction with colleagues and administration based on differences of the opinions, the way educational load is being shared;

- the way a teacher interacts with the child's parents in case of differences in estimation him or her by the teacher and the parents.

To remove emotional tension and develop emotional stability, it is important to form tolerance as a professionally important quality of a teacher's personality in general, and primary school teachers, in particular. By pedagogical tolerance N.P. Kozynets understands abilities and skills of tolerant interaction with every individual of the educational process; setting the task of fostering tolerance as an active position in forming one's own tolerance, the tolerance of pupils and their parents; the norm of behavior as one of the components of pedagogical ethics. Pedagogical tolerance is a social category and manifests itself in the setting for recognition of another person, empathetic understanding, open and trustful communication [8, p. 39]. 
Analyzing specificity of tolerance in the educational process, I. I. Sorokin identifies two types of tolerance of primary school teachers: social and a psychological one. Social tolerance allows the teacher to effectively interact with all participants in the educational process, and the formation of psychological tolerance provides high resistance to numerous professional stresses and promotes the effective development of a professional career $[17$, p. 2].

Within social tolerance I. I. Sorokin suggests to distinguish two structural components: dynamic and operational. Dynamic side of tolerance is determined by the proportion of the teacher's motivational sphere, the system of his or her values, interests, beliefs and social attitudes. Operational basis of social tolerance is determined by specific knowledge, skills and abilities [17, p. 3].

Educational tolerance acts as an integrative form that bears the traits of all types and levels of tolerance, determined by the goals, objectives and characteristics of the teacher's educational activity and all the variety of pedagogical situations. The elementary school teacher acts as an educator who teaches and learns oneself. He or she is engaged in a few types of interaction, namely, teacher-teacher interaction, teacher-student interaction and teacher-parent / mother/father-teacher interaction, which influences the parent-child relations.

Educational tolerance is directly related to interaction. Tolerances is fostered in such types of interaction as dialogue, collaboration, tutelage; on the contrary, suppression, indifference, confrontation, conflict ruin it.

Dialogue displays individuality; it allows to see the peculiarities of another individual as it is dialogue interaction that presupposes equality of positions of everyone in communication. In the structure of a dialogue interaction, emotional, strong-willed and cognitive components prevail, which can be characterized by a high level of empathy, a sense of partnership, lack of stereotypical perception of others, flexibility of thinking, ability to adequately «accept» one's own personality.

Collaboration assumes mutual development of aims of interaction, allocation of duties and resources according to everyone's possibilities. It is manifested in behavior through the ability to contact, benevolence, absence of anxiety, mobility of actions, politeness, patience, trust and social activism. 
Tutelage is a kind of interaction relating to the concept of tolerance. Tutelage implies care without humiliating those who are under guardianship, which is the norm of interaction.

The signs of this type of interaction are emotional stability, high level of empathy, social activism, and ability to come to the rescue.

Hence, O.A. Matiienko assumes that the criteria for pedagogical tolerance should be motivation for cooperation, dialogue, development of the mechanism of recognition, assertive behavior [12, p. 30].

The main aspects of the problem of tolerance are most clearly manifested in communication, or communicative tolerance. Communicative intolerance is found in situations where communication partners are at different levels of development and perception of reality.

The communicative tolerance of a primary school teacher is evident through his or her ability to build educational communication at the level of a dialogue, equal relations, trust and goodwill. It is important to note that equality in the educational process is also possible. After all, equality in relations and fulfilling social roles are different things.

Indeed, role behavior of a schoolteacher implies some distance from his or her students, but the distance implies a horizontal position, it should not be associated with climbing on the pedestal, from which communication begins. The role of a teacher often binds him or her to give instructions, while role of that one whom the instruction are directed to, is to accept them. But since everyone finds oneself performing different roles, it is possible to understand, see and feel what is happening at the moment with other people and in what way we can change ourselves, our language of communication, our doings and responses as well as feelings, thoughts and states of other people around us.

Structure of a tolerant attitude of a teacher towards pupils of primary schools can be presented in the form of interaction of three leading components:

- the conceptual-and-value component of teacher's tolerance is revealed through the system of principles, according to which his or her educational process is organized, the dominant ones of which are the following: the idea of spiritual freedom of a person; recognition of the fact that every child is original and unique; belief in the inexhaustible capacities and abilities of an individual; respect for human dignity; 
- the activity-and-behavioral component of a teacher's tolerance is revealed through a system of ways of his or her pedagogical actions concerning organization, control and evaluation of the quality of activity of students as participants of the educational process, that include recognition and perception of the individuality of each child; granting the inviolable right to personal opinion; assessment of a personality according to selfconcept;

- the personality-motivational component of a teacher's tolerance is manifested by the nature of his or her emotional attitude to the participants of educational interaction, namely: benevolence, courtesy, sincerity, loyalty, restraint, charity, empathy and justice [11, p. 131].

System of tolerant relations between the teacher and children consists of three inseparable parts: understanding, recognition and acceptance of a child. Understanding is the penetration into the inner world of the child through feelings and logic. The most important need of a child is to be properly understood, accepted and recognized in every its manifestation. If a teacher does not see a unique identity in his or her pupil, he or she is not able to bring the child up. The teacher will not have a "platform" to establish contact with his or her pupil.

To get result in the process of understanding his or her pupils, an elementary school teacher should poses the following professional qualities:

- observation and understanding of the educational process events;

- empathy, that is, unconditional empathy, understanding the feelings experienced by a pupil and adequate expression of his or her own feelings;

- ability to be constantly aware of and properly respond to the fact how he or she is perceived and evaluated by the pupils as a teacher;

- understanding of typical mistakes teachers most often make when assessing the appearance and inner world of pupils;

- the ability to practically apply assessment characteristics to compare changes resulting from educational actions $[16, \mathrm{p} .5]$.

Recognition of the right of a child to be oneself is a reconciliation of the teacher with the child's personality, views, assessments and position. The requirement to recognize a child is based on the belief in its capacity and self-improvement in future. Only such an understanding of the dialectics of the contradictions of education makes a teacher wise and patient, and his or her position as strong and invulnerable. Only then, the pupil naturally 
goes through all the periods and difficulties of adulthood, having no more consequences and complexes, which have been possibly formed before by previous improper upbringing.

If a teacher accepts the children, he or she also accepts their individual peculiarities and disadvantages, without distinguishing or evaluating them, recognizing its right to be themselves. If a teacher does not recognize a pupil or recognizes him or her formally as his or her service need to, a teacher will fail. Modern school relations are often characterized by incomplete recognition of a child because a pupil is constantly conditioned. As a result, a primary school pupil experiences unrealistic views of oneself and people around him or her because of low levels of self-estimation, uncertainty and feeling of hopelessness.

If the demands on the child are unjust, overstated or understated, if it is constantly condemned, then the protest is inevitably growing, and dissatisfaction with oneself is developing. Recognition is grounded on the demand and principles, based on a positive attitude and willingness to help. The state of unconditional recognition favors maximum the self-affirmation of the child, giving him or her free hands for self-regulation.

In order to exercise tolerance in the interaction with schoolchildren, teachers must, first of all, create models of relations among themselves, namely: to work in an atmosphere of mutual understanding, mutual respect and empathy. A tolerant educator is aware that he or she is perceived as a model to follow. He or she uses his or her skills to develop dialogue and to solve peacefully conflicts, teaches to think critically, is able to value the views of others clearly articulating his or her own point of view, does not support abusive behavior and favors the involvement of pupils and parents in decision-making activities [16, p. 6].

Pedagogical tolerance is, first and foremost, an active position that is formed on the basis of the recognition of the universal rights and fundamental freedoms of every pupil. The teacher advocates the humanization of the social environment, all means of education, formation of one's own personality, capable of bringing all these ideas to life, into the real practice of teaching and educating the younger generation on the ideas of peace and understanding.

Undoubtedly, tolerance is better manifested by altruistic teachers who genuinely love children are able to interest and awake a variety of feelings, 
not just form knowledge and skills. It is important to perceive the child not with criticism, but with optimism and belief in his or her natural abilities and successes. In order to develop a system of education on the ideas of peace, tolerance and understanding, it is necessary to find new effective methods of humanization of the social environment, means of education, the formation of the personality of the teacher able to translate all these ideas into life, into the real practice of teaching and upbringing younger generation on ideas of mutual understanding.

Thus, tolerant relations between elementary school teachers and their pupils are based on the conditions created by the teacher for pupils selfstudy, formation their positive attitude towards learning focused on their multicultural motivation, orienting children to an adequate perception of teacher's assessment. All this favours increase of efficiency of the educational process, lessons being carried on in an atmosphere of respect, warmth, humanity, comfort and the perception of each pupil as a subject of study with stable moral and spiritual principles.

\section{Formation of a tolerant attitude in the family}

One of the challenges of a family upbringing is the violation of tolerance in the relations between parents and children. Psychic and physical health of a human being is closely related to a family. Family conflicts not only disorganize and ruin a family but also cause the basis of accumulation of deviant potential of a child. Because of unrecognition of their rights to freedom of actions, choice of ideals and individuality children lose the ability to mutual activity resulted in emotional violations, constant anxiety and deviation in behavior of different types. As a rule adults do not see any prospects of complicated relations with children and do not evaluate their impact upon formation and development of a child as a personality.

A family is the institution of upbringing where the base of a person's morals starts from, principles of interaction in the society as well as correction and evaluation of one's own actions take place. Naturally, school has a great upbringing potential, but the family and the child's individual peculiarities are the two main determining factors in personalization [20, p. 91].

That is why the level of modern culture tastes parents the task to learn to solve conflicts with their children using the principals of tolerance. Strong family with traditions and tolerant relations between parents and children 
neutralize negative influence of the environment. For instance, propaganda of violence and cruelty that come through some media are neutralized with parents' understanding and care. Attentive attitude of adults to children's views, interests and hobbies have positive affect upon the process of socialization of younger generation.

Tolerance is a complicated notion that has many aspects. Tolerance is communication and freedom of thinking, conscience and beliefs, harmony in diversity, virtue that makes it possible to achieve mutual understanding between people, parents and children in a peaceful, conflict free manner $[18$, p. 42].

To bring up a tolerant child one should take into account that children are the mirror of nature and attitude between their parents. That is why it is necessary, first of all, for parents themselves to be tolerant to their own children. Parents will be able to form children's value system, the basic notions of which are compromises, tolerance, forgiveness, nonviolence, sympathy, understanding, empathy in case they themselves profess these values.

Tolerance between children and parents in the family is a kind of direction for perception, mutual understanding and actions of adults and children based on respect to interests, values and positions of every member of the family. Besides, it means the ability of parents to understand the effects of the influence of family relations upon the child, its development and behavior in general.

Next sign of tolerance in relations between children and adults is for adults to give up the so called monopoly for «knowing the truth» in solving the problems that appear and as result of it the position of shifting the guilt of their mistakes upon their child. We have intolerance in case when the parents are always "true" and children are "wrong".

O. M. Kramareva considers that parents' tolerance begins with their love, understanding and respect to one another. "The most important thing that you can do for their children is to love one another" [9, p. 28]. The educator thinks that parents should be "heroes" for their children. Those persons, which children would like to follow. "A hero is a father or mother who manifests such a nature, sensitivity, honesty, which allow them to be the person to follow. You must become a hero for your child to prepare him or her to full life in modern unhealthy, evil world" [9, p. 28]. 
You can teach children to be responsible, disciplined, truthful, and honest only by your own example. In no case, parental duties can be reduced to guidance and punishment. Instead, you should direct your efforts to the other side: think how and for what you can praise, encourage, and support the child. No matter how busy parents are, there should always have time for children, no one and nothing can be more important for parents than children.

Tolerance in the relationship between children and parents does not demand the parents to give up their own views, values and ideals. Tolerance in the relationship between the members of the family assumes combination of persistence (of both children and parents) as an ability to realize their personal positions and flexibility that is their respectable attitude to positions and values of each other.

Important feature of tolerance in the relationship between children and parents is mutual analysis of actions of the members of the family, both children and adults. Regarding tolerance in the relationship between members of a family as a feature of tolerant relations, one can underline active interaction between its members on the bases of mutual respect and support. It is necessary to listen to child's thoughts and take them into account, to be able to forgive insult and to make an apology to the child. This is the most difficult moment but the most important one as children have sharpened feelings of justice.

Tolerance favors the ability to negotiate without quarrel and "ruining conflicts" under which there is meant the confrontation, which injures morally and physically. In our everyday life, we cannot avoid conflict of interests, wishes and thoughts. That is why it is important to redirect the conflict into constructive dialogue and to involve children into taking mutual decisions.

The relationship in the family can be spontaneous, influenced by a variety of factors. This process can be purposeful if the task of fostering tolerance in the relationship of children and their parents is regarded as one of the tasks in organizing the educational work of elementary school teachers within the family. According to S.V. Stefantseva, its success depends on the implementation of the following principles in the activity of the teaching staff $[18$, p. 47]:

1. The principle of subjectivity requires reliance on the activity of the family members, stimulation of their self-education, conscious behavior and self-correction in relations with other people. The conditions for implementing this principle are: 
- voluntary involvement of the family in certain activities;

- trusting on the family the choice of means for achieving the goal as belief in the potential of each family member to self-cultivated tolerance;

- taking into account the interests of family members, their individual tastes, preferences and encourage them to form new interests.

2. The principle of conformity requires conformity of the content and means of education to the social situation, in which the educational process is organized. The tasks of education are focused on the real relationships that develop between different family members. The conditions for implementing this principle are:

- relevance of educational tasks to real events occurring in the nearest environment;

- coordination of interaction between social institutions that influence the formation of value orientations of the family as a whole and its individual members;

- correction of the perceptions of various information by members of the family, including information from the media.

3. The principle of individualization assumes determination of the individual trajectory of education of tolerant consciousness and behavior, allocation of special tasks appropriate to the individual characteristics and the level of tolerance in the child and its family members; finding out individual approach to every member of the family as to involvement in various activities to discover potential of the individual, empowering each family member to realizing their potential. The conditions for implementing the principle of individualization are:

- monitoring of the changes in tolerant consciousness of family members;

- choice of special means of influence on each family members;

- account of individual qualities of each family member, his or her value orientations in the choice of educational means aimed at the development of tolerance.

4. The principle of the reflexive position assumes an orientation towards the formation in children and their parents of a conscious stable system of attitudes towards the problems significant for them, issues that are manifested in certain behavior and actions. The conditions for implementing the principle of reflective behavior are: 
- encouragement of children and their parents to self-analysis of their attitude to people around, to compare their own actions with their own statements;

- to carry out, together with the experts, analysis of the ways of various problems of social relations in real and simulated situations (social tests) have been solved;

- self-assessment of one's own actions and prediction of the relations with people around and their family members in future;

- assisting children and their parents in the analysis the problems of social relations and behavior in difficult life situations related to relations between them.

5. The principle of creating a tolerant environment assumes mutual responsibility of participants in the educational process, empathy, mutual assistance, the ability to overcome difficulties together. In the course of the work, creative endeavors dominate, creativity being considered as a universal criterion of assessment of an individual and relationship in the family.

The implementation of this principle is carried out under the following conditions:

- adoption of general rules of relationship, uniform for all family members;

- empowering everyone for self-realization and self-expression;

- identifying leading activities that are meaningful to all family members;

- forming a positive attitude towards creativity (a tolerant environment must be heuristic).

To nurture tolerance in the family means to instill respect, acceptance and a correct understanding of the rich diversity of cultures of the world, forms of self-expression and ways of manifesting human individuality. The main methods of upbringing in the family are, for instance, when children and their parents do different kinds of jobs together, maintain conversations, supporting of the child in different cases, in solving problems, involving it in different activities within and outside the family [15, p. 25].

Thus, the formation of tolerance as one of the most important personality traits occurs in childhood in the family and educational institutions and lasts throughout life in the process of education. The cornerstone of pedagogical influence on the cultivation of tolerance in the relationship between parents and children are the principles of subjectivity, conformity, individualization, reflective position and creation of a tolerant environment. 


\section{Conclusions}

Currently, scientists keep to alternative points of view on the problems of understanding the nature and content of tolerance and the process of its formation. Tolerance has a poly-scientific nature and is defined as an integral characteristic of an individual, which consists of the ability of a person to actively interact with the external environment in critical situations in order to restore one's neuro-psychic balance, successful adaptation, the development of positive relationships with oneself and with the world.

One of the social institutions contributing to the formation of a tolerant attitude is education, which fruitfully uses dialogue, cooperation and respect between all participants of the educational process. Tolerance is a complex concept that touches on issues of moral and ethical nature and belongs to the professional traits of elementary school teachers. Pedagogical tolerance is revealed through the skills of tolerant interaction with all the participants of the educational process. Pedagogical tolerance can be expressed through a socio-cultural approach and is necessarily linked to the process of communication.

Tolerance in the relationship between children and parents helps to listen and understand each other, to accept people as unique, to understand everyone's right to his or her own vision of the world. Educators' interaction with parents as to formation of tolerant attitude towards children in the family is a multidimensional problem, which involves solving such issues as developing relationship and communication in the family, level of parents' awareness on the problem of tolerance as the most important value of society and their willingness to use the knowledge in their behavior.

Prospects for further research of the theme concern the factors influencing the formation of tolerance of primary school teachers and parents of children of primary schools and investigation of pedagogical conditions to elevate its level.

\section{References:}

1. Achasova, L. Ju. (2018). Tolerantnost $\mathrm{v}$ deiatelnosty sovremennoho pedahoha [Tolerance in the activities of a modern educator]. Pedahohycheskoe obrazovanye y nauka, no. 11, pp. 23-28.

2. Kovalova, T. V. (up.) (2013). Velykyi tlumachnyi slovnyk ukrainskoi movy [A great explanatory dictionary of the Ukrainian language]. Kharkiv: Folio.

3. Vykhrystiuk, M. (2017). Tolerantnist yak neviddilnyi aspekt vykhovannia dytyny [Tolerance as an integral aspect of child-rearing]. Pochatkove navchannia $i$ vykhovannia, no. 19/20, pp. 70-72. 
4. Vyshnevetska, Ye. (2017). Rozvytok tolerantnosti yak aktyvnoi zhyttievoi pozytsii [Development of tolerance as an active life position]. Ridna shkola, no. 10. pp. $38-41$.

5. Haidamashchuk, M. (2015). Tolerantnist yak osnova formuvannia tsyvilizovanykh stosunkiv [Tolerance as the basis for the formation of civilized relationships]. Uchytel pochatkovoi shkoly, no. 12, pp. 53-55.

6. Dvoretska, H. V. (2015). Sotsiolohiia [Sociology]. Kyiv: KNEU. (in Ukrainian)

7. Deklaratsiia pryntsypiv tolerantnosti. Retrieved from: http://don.kievcity. gov.ua/files/2/10/Deklaracija-tolerantnosti.pdf (accessed 25 March 2020).

8. Kozynets, N. P. (2019). Shcho take tolerantnist? [What is tolerance?]. Klasnomu kerivnyku. Use dlia roboty, no. 9, pp. 38-42.

9. Kramareva, O. (2017). Suchasna kultura tolerantnoi osobystosti [Modern culture of tolerant personality]. Dyrektor shkoly, no. 17, pp. 26-30.

10. Krejn, I. (2016). Kontseptsiia tolerantnosti yak universalnoi katehorii evoliutsii rozumu: metapidkhid [The concept of tolerance as a universal category of the evolution of the mind: a meta-approach]. Visnyk NAN Ukrainy, no. 11, pp. 22-42.

11. Lopushnian, H. A. (2019). Model tolerantnosty pedahoha v svete kontseptsyy yndyvydualnosty [The concept of tolerance as a universal category of the evolution of mind: a meta-approach]. Pedahohyka, no. 1, pp. 128-134.

12. Matiienko, O. (2018). Vykhovannia tolerantnosti pochynaietsia z uchytelia [Educating tolerance begins with the teacher]. Pochatkova shkola, no. 6, pp. 29-32.

13. Todortseva, Yu. V. (2017). Pedahohika tolerantnosti [Pedagogy of tolerance]. Odesa: PNTsAPNU. (in Ukrainian)

14. Orlov, A. B. (2016). Psykholohyia tolerantnosty: problemy i perspektyvy. [Psychology of tolerance: problems and prospects]. Voprosy psykhologhyy, no. 3, pp. $12-16$.

15. Ponomarova, V. (2016). Osoblyvosti formuvannia tolerantnosti u simi [Features of forming tolerance in the family]. Pochatkove navchannia $i$ vykhovannia, no. 4, pp. 22-26.

16. Savchenko, O. (2018). Vchymosia tolerantnosti [We learn tolerance]. Uchytel pochatkovoi shkoly, no. 9, pp. 4-8.

17. Sorokin, I. I. (2019). Tolerantnist yak odna z dominant pedahohichnoi nauky [Tolerance as one of the dominant pedagogical sciences]. Uchytel pochatkovoi shkoly, no. 1, pp. 2-3.

18. Stefantseva, S. (2015). Tolerantne spilkuvannia na rivni «Batky - dity» [Parent-to-child tolerant communication]. Pochatkova shkola, no. 21, pp. 42-49.

19. Stoliarenko, O. (2017). Tsinnisne stavlennia do liudyny: vykhovna model tolerantnykh vzaiemovidnosyn uchasnykiv navchalno-vykhovnoho protsesu [Valuable attitude towards an educational model of tolerant relationships of participants in educational process]. Ridna shkola, no. 3, pp. 47-52.

20. Fedosieieva, D. (2019). Tolerantnist pochynaietsia z simi [Tolerance begins with the family]. Shkola, no. 7, pp. 91-96. 